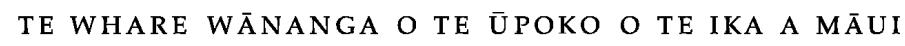

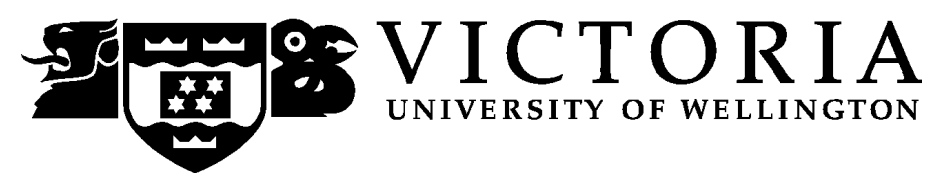

\title{
A Roadmap to Virtual Fieldtrips
}

\section{Lessons learned from developing a virtual Fijian island for fieldwork by Tourism Management and Development Studies students at Victoria University of Wellington}

Project Leader: Dr Christian Schott

With: Prof Warwick Murray, David McLean, Maciu Raivoka

Project Funding: VUW Learning and Teaching Development Fund 2011 


\section{Table of Contents}

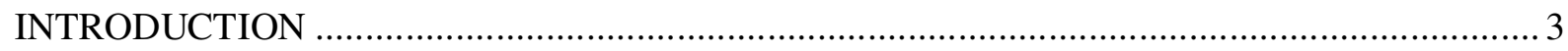

PEDAGOGIC RATIONALE FOR DEVELOPING VIRTUAL FIELDTRIPS ................................ 3

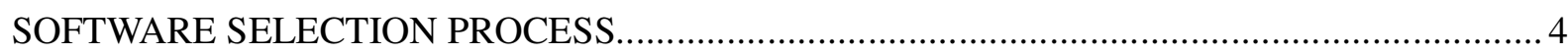

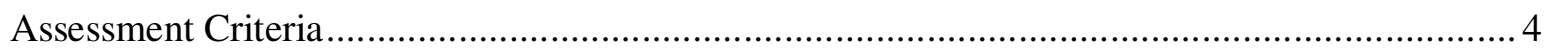

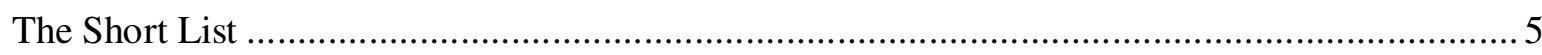

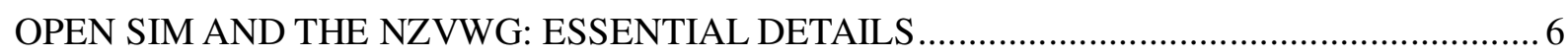

Viewers Required to Run Open Simulator ....................................................................... 6

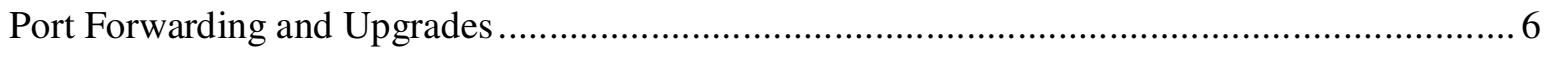

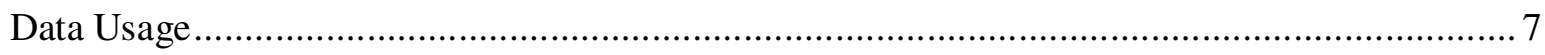

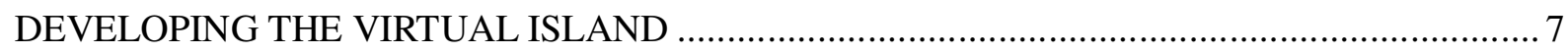

Scale of the Virtual Island ...............................................................................................

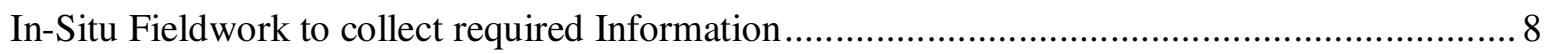

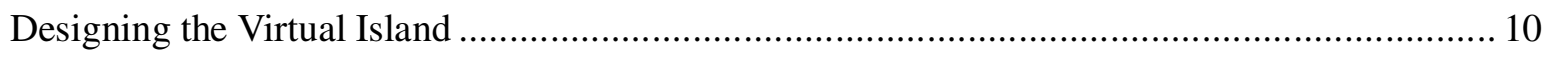

Infusing the virtual island with real-world videos and photographs........................................... 11

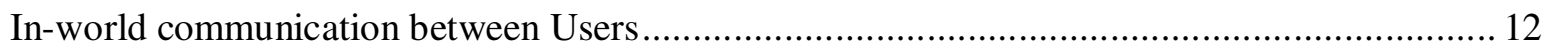

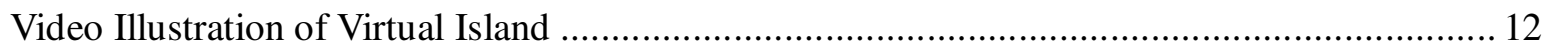

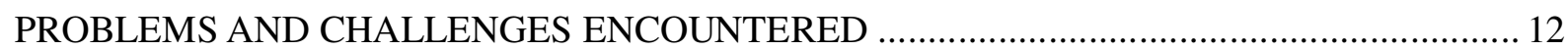

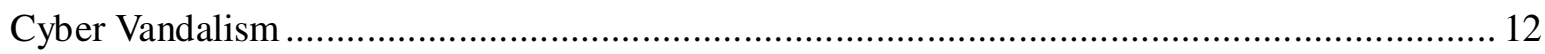

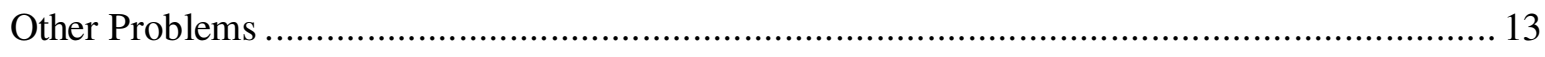

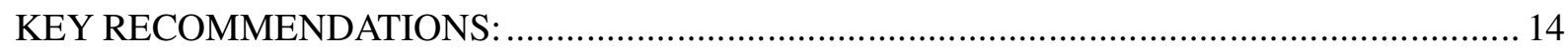

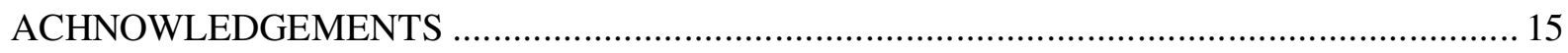

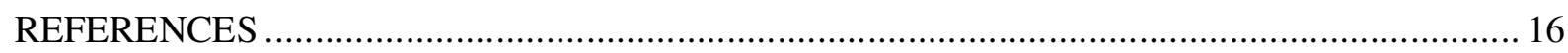




\section{INTRODUCTION}

Fieldtrips are an important pedagogic tool for a range of disciplines. Indeed the pedagogic value of experiential and situated learning was already promoted in the 1940s by the educational philosopher John Dewey (1968). It is widely recognised that such trips allow students to benefit from the rich experiential learning such endeavours entail and that situated learning environments assist in crystallising learning outcomes (Jakubowski, 2003; Scarce, 1997).

However, today's university environments are resource-constrained and traditional residential fieldtrips have become less common. In response, we propose that the concept of 'virtual' fieldtrips presents a potentially powerful tool, which if designed and applied appropriately, might replicate some aspects of the 'real' fieldtrip experience. A virtual fieldtrip attempts to recreate aspects of the real world in digital format where assignments and tasks similar in nature to those set in the residential fieldtrip environment would be applied (virtual fieldwork). During the virtual fieldtrip the student (in the form of an avatar) is digitally immersed into the social, cultural, economic and environmental landscapes that 'make' places - something which is only possible at present through residential fieldtrip activity. While this project does not propose that traditional residential fieldtrips can be replaced by virtual fieldtrips, we believe students going on a virtual fieldtrip and conducting virtual fieldwork are exposed to at least some of the valuable nuances of 'real' fieldwork.

In particular, in disciplines such as Tourism Management and Geography the value and indeed need for these forms of situated and experiential learning is well established, however, the concept of virtual fieldtrips also offers valuable learning environments for other disciplines. It is important to note here that virtual reality software such as Second Life has been used by educational institutions for many years, with the most frequent use for role play-based learning; for an overview of different educational uses of Second Life see this document http://piensl.pbworks.com/f/slliteraturereviewa1.pdf by Salt, Atkins, Blackall (2008). However, the concept of virtual fieldtrips and the related student task of virtual fieldwork is shown by the literature to be a novel use of virtual reality software; and the experience of developing such a learning tool is thus worth researching and sharing.

\section{PEDAGOGIC RATIONALE FOR DEVELOPING VIRTUAL FIELDTRIPS}

The choice of a developing country as the destination for the virtual fieldtrip was driven by the need for it to serve both Development Studies as well as Tourism Management students as a learning tool. The following three learner-centred goals are the main pedagogical drivers for the project. These goals are considered in relation to common teaching and learning approaches utilising for example text-based case studies from a textbook:

- Enhance authenticity of the learning context and expose learners to the multitude of complexities and dilemmas facing communities in developing countries

» by digitally immersing students in a multi-dimensional, multi-stakeholder, integrated case-study informed by two communities on a remote Fijian island

- Foster an acute sense of the interconnectedness of social, cultural, environmental and economic factors impacting the communities as well as of the wide-ranging interests of different stakeholder groups linked to the communities.

» by representing the different stakeholders and above-factors in as authentic a manner as possible: video clips of different stakeholders expressing their opinions, rather than a researcher-compiled summary of opinions; original documents rather than extracts, other factual information in the form of photographs, objects or signs which encourage students to 
do further research and to make connections and thus unravel some of the complexities underlying life on the island. Importantly, all this information is contextualised by the digital visualisation of the community, the village and the island.

- Increase access and passion for learning

» by integrating a variety of technologies that are increasingly part of everyday life for today's twenty year olds (video game technology, video clips, text messaging, etc) as well as by using a mix of learning media (audio, video, photographic, 3D, text, interactive, etc) to appeal to a range of learning styles.

\section{SOFTWARE SELECTION PROCESS}

To allow for the best available software option to be enlisted for the purpose of developing this project the first project phase consisted of identifying all potentially suitable software. From this search the ten software programmes below were shortlisted:

A Active Worlds

A Adobe Flash

A Muse

A NZVWG (New Zealand Virtual World Grid)

A Open Simulator

A Second Life

A SmallWorlds

A Unity

A Unreal

A Worlds.com

\section{Assessment Criteria}

All ten software programmes were systematically assessed by the project's technical Research Assistant, David McLean, against a table of criteria which was developed from the project team's vision of the ideal virtual fieldtrip learning tool. The assessment criteria that the programs were tested against were as follows:

A User Friendliness - how aesthetically pleasing the software looks and how easy it is for the users of the software to navigate the virtual worlds.

A Adaptability - ability to incorporate videos and images into the virtual world. The software also needed to allow for content to be editable at a later stage.

A Versatility - ability to be used by other disciplines and faculties for similar purposes

A Interactivity - ability for users to communicate in-world by use of text messaging or verbally

A Time effectiveness - the necessary tools to create the virtual world had to be as easily accessible and as time efficient as possible.

A Other areas of consideration were: the projected longevity of the software, whether or not the virtual worlds can be protected from potential harm, whether or not the student 
computers at the university can run the software well (graphics and bandwidth) and also the likely overall costs of initially developing, and then maintaining the virtual world.

For each of the criteria it was considered important to distinguish between three different project dimensions: the initial building phase, the ongoing maintenance, and the daily use by learners.

Each of the criteria was ranked on a scale of 1 to 5, with 1 being the lowest score and 5 being the highest. See more detail about the selection criteria and scoring matrix in Appendix 1.

\section{The Short List}

As a result of the above-described process the technical RA identified three programmes that most closely met the requirements:

- Second Life

- Open Simulator/NZVWG (New Zealand Virtual World Grid)

- Active Worlds

Second Life and Open Simulator are very similar pieces of software. The major difference between them is that Open Simulator is open-source software that is free to be used by anyone, whereas Second Life charges educational institutions fees, some of which are ongoing. In comparison to these programmes Active Worlds is considered dated in appearance and in software creation; it also required educational users to pay both a setup up and an annual fee

The three programmes were demonstrated and assessed by the project team. The programme considered most appropriate for the project was the Open Simulator because of the following key benefits:

- Open Simulator is an open source version of the popular virtual world programme 'Second Life' and therefore in step with progress in virtual world software and appeal to users.

- because the software is open source it does not incur any charges, neither for developing nor for use

- $\quad$ servers were not required because the project was able to join a recent Open Sim digital learning initiative called the New Zealand Virtual World Grid (NZVWG, primarily used for role play by Medicine and architectural design by Architecture) which led to a server at the University of Auckland hosting the virtual island.

- Auckland University (ITS) also offered technical support for the project which was important because VUW ITS does not employ staff who can provide technical support for virtual worlds.

- the programme's software and hardware requirements were met by VUW student computers in the Railway Station (Pipitea Campus)

- on campus the programme could run on the Kiwi Advanced Research and Education Network (KAREN: a data network providing high capacity, ultra high speed connections 
between New Zealand's universities) rather than being reliant on public Internet connectivity. However, it could also be run by off-campus computers using public Internet facilities.

- the programme possessed the required tools (land and object creation) to develop the virtual world in a time efficient manner

- The virtual world can also be updated by amending and refreshing certain components to retain the case-study's relevance in years to come.

\section{OPEN SIM AND THE NZVWG: ESSENTIAL DETAILS}

URL: http://nzvwg.org/

\section{Viewers Required to Run Open Simulator}

Open simulator is the software that runs the virtual world, but the software requires another program called a 'viewer' to view the virtual world. Here is a list of the viewers we tested:

Phoenix - Functioned reasonably well, but some of the interface is bulky and the overview maps regularly fail display properly.

Hippo - On most accounts superior to Phoenix. A particular strength is that the overview maps consistently displayed properly and with a high level of detail.

Imprudence - Very similar to Hippo, with a slightly different user interface design.

How to configure these viewers in order to access the NZVWG is explained here:

http://nzvwg.org/index.php/getting-started

\section{Port Forwarding and Upgrades}

ITS staff at Victoria University assisted in connecting the University computers to the NZVWG, as well as upgrading certain software required to run the project as effectively as possible. Specifically, ports needed to be opened to connect to the KAREN network (as outlined above), which connects all projects on the NZVWG. The relevant IP addresses are:

A cecvwgp04.cecil.auckland.ac.nz (130.216.15.135)

A cecvwgp03.cecil.auckland.ac.nz (130.216.15.40)

A cecvwgp02.cecil.auckland.ac.nz (130.216.15.157)

A cecvwgp01.cecil.auckland.ac.nz (130.216.15.156)

And the communication ports for these addresses were: 9000 to 9013

Below is a list of upgrades actioned by ITS in July 2011 in order to optimally equip student computers in the Cybercommons in Railway 102 and 202 (Pipitea Campus):

A update graphics driver 
A deploy Phoenix Viewer software to group of PC's (now we recommend: Hippo Viewer instead)

A add the Java runtime for non IE browser in order for the "in game" browser to be functional to view videos streamed from You Tube (actioned in August 2011)

\section{Data Usage}

The Open Simulator software requires access to the Internet and constant downloading of the virtual world's contents

A Settings for the virtual world can be user defined. Options range from Low (low quality textures and low view distance) to Ultra (high quality textures and long view distance)

A According to our basic tests Low settings require roughly $40 \mathrm{MB}$ of data per hour, whereas Ultra settings require roughly $200 \mathrm{MB}$ per hour. Data usage also depends on what the user does while using the software.

A We strongly recommend that this information be communicated to students in case they would like to access the NZVWG using their personal Internet provider from their home computer

\section{DEVELOPING THE VIRTUAL ISLAND}

\section{Scale of the Virtual Island}

The creation of the project began with a detailed assessment of the Fijian island's size relative to server capacity and practicality considerations in order to determine how many regions (parcels of land in Open Sim) would present the most appropriate number to develop the virtual island. At the same time, consideration was given to the scale at which the island and its detail would be created as the relative size of objects and distances between villages and facilities are important features of a virtual fieldtrip. After discussion with the server manager (Dr Scott Diener, Associate Director, IT Services at Auckland University), the decision was taken to develop the virtual island at a scale of roughly 1:3. At this scale the virtual island is spread over eight regions with the most notable exception to the 1:3 scale being applicable to the two regions connecting the two villages where only a approximately 1:5 scale could be achieved (see Figure 1); while the change in scale is not accurately reflective of the island, the key messages about distances are still clear through the use of signs. The benefits of developing the virtual island at this scale and in this manner are: i) that while all the significant detail and information is still placed in its appropriate context it is believed that students are less likely to lose interest in exploring the island than if it took three times as long to walk from point $A$ to point $B$, ii) that lesser demands are placed on the server than if more regions were utilised for the virtual island; VUW's Virtual Fieldtrip project is currently the largest project in NZVWG in terms of regions, most other projects use no more than four regions. 


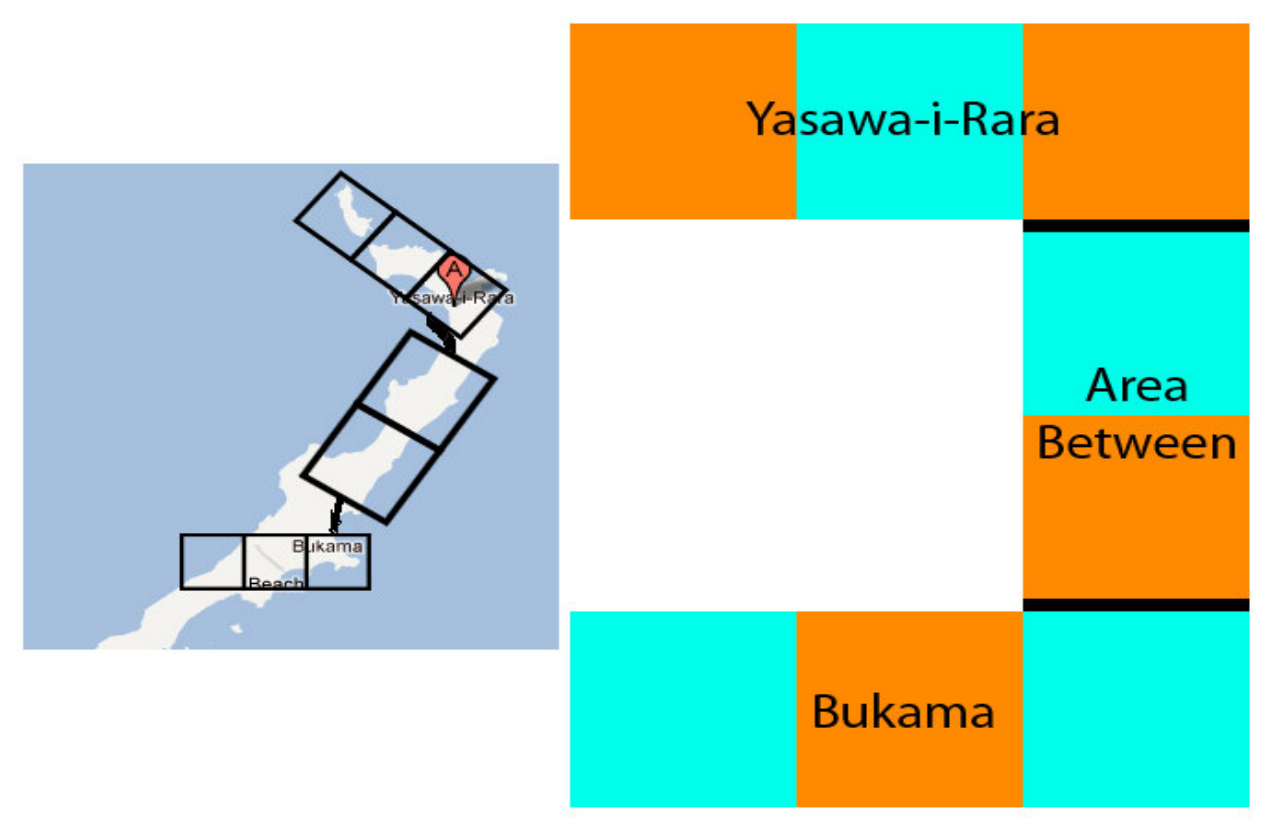

\section{In-Situ Fieldwork to collect required Information}

After seeking and obtaining approval for this culturally-sensitive research by Pipitea Human Ethics Committee, the Project Leader, Christian Schott, and the cultural Research Assistant, Maciu Raivoka, travelled to the Fijian island in June 2011 to gather all the required information for the project. In order to develop the virtual island as an effective learning tool the project enlisted a method used to develop text-based case studies. The method is devised by Tyson (2008) who is the principal case writer for the Australia and New Zealand School of Government Case Programme, which has a database of more than one hundred case studies. The method (Table 1) was adapted for the project by focusing on a digital-immersion presentation of the case, rather than a structured textual account, and by focusing on the points relevant to a decision-forcing case, rather than a concept-application or illustrative one.

Note: This roadmap documents the 'technical' process of developing a virtual fieldtrip to Fiji. For more information about the cultural considerations and challenges encountered please contact Maciu Raivoka (Maciu.raivoka@vuw.ac.nz) 
Table 1 - The Case Planning Pyramid (adapted from Tyson, 2008)

\section{Background - macro}

- Information about geographical location and features

- Information about tourism and other development on the island

- Relativities: e.g. populations size, economic dynamics, health care, education, role of church, etc

- Political and cultural aspects to be considered

\section{Background - more specific}

- Recent initiatives and/or projects relevant to Tourism Management and Development Studies

- Variety of stakeholders' views and opinions tourism development and development more broadly

- Information from influential stakeholders as well as members of the community who do not hold influential positions

- Information about key events: e.g. new legislation, natural disasters

\section{Dilemma or decision}

- Any dilemmas need to be identified and related material needs to be collected

- Develop the range of key decision avenues: examining the factual aspects from a disciplinary perspective and by listening to the voices of a wide range of stakeholders

- Identify and collect information which is authentic and provides support for the identified decisions avenues

Different media were employed to document the above; some information was collected to be used in (as much as possible) an unmodified way in the virtual world, while other information served to guide the digital design of the environment and objects on the virtual island. The following media were used:

- Videos with audio

- Digital Photographs

- Print Film photographs (underwater)

- Digital Excel data spread sheets (e.g. tourism statistics)

- Digital Word documents/pdf documents

- Hard copies of important documents (e.g. evacuation plans)

- Digital map files 


\section{Designing the Virtual Island}

The first step was to create the rough shape of the island with the tools within Open Simulator. Each of the eight regions are square and were arranged in a horseshoe shape as the island itself has a similar outline. Using a map of the real island as a guide each region was shaped to reflect the basic geography of the real island. This was followed by shaping the topography of the different regions and defining islands; see example in Figure 2.

Figure 2 - Example of early stage of creating the island

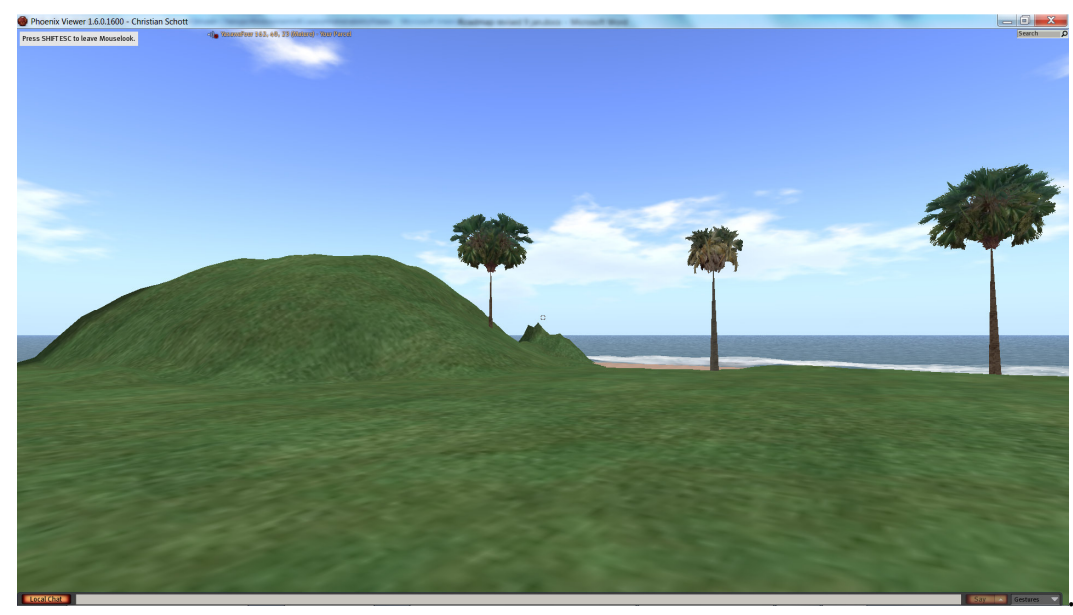

The next step was to add buildings and the vegetation. Some of the buildings had to be specifically created for this project and could not be copied from a library as the distinctive identity of the island had to be represented. Such buildings included the chiefly houses, the community hall, the Church Minister's house, island bures, and school buildings amongst others. The buildings were created in the virtual world using the software's creation tools (see Figure 3).

\section{Figure 3 - The Yasawa-i-rara community hall, both real and virtual}

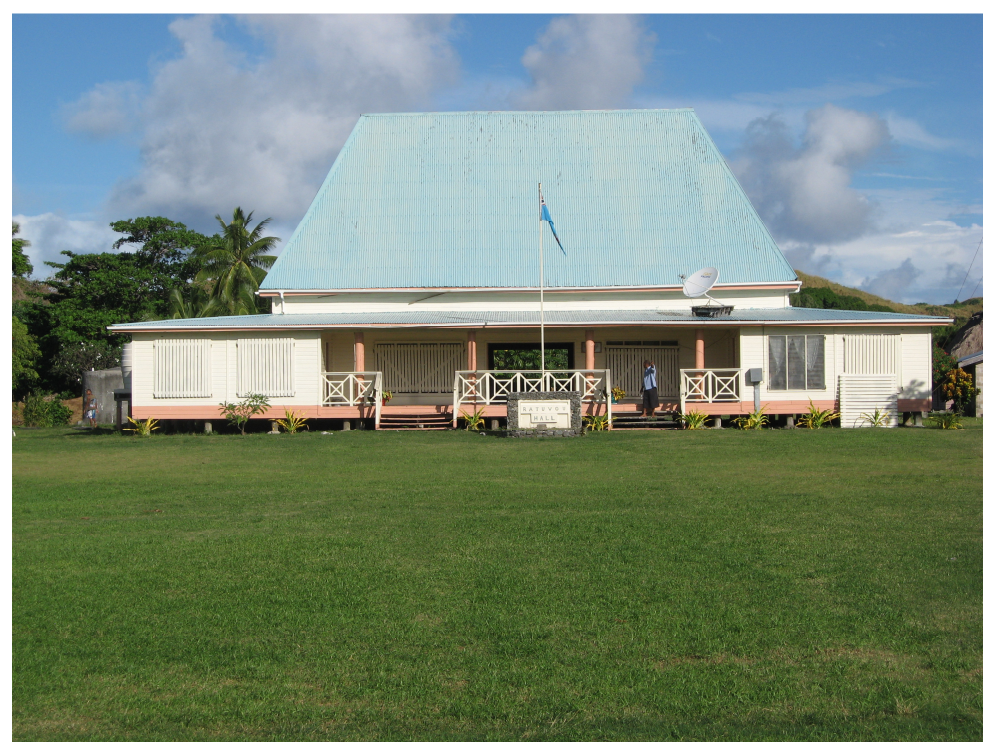




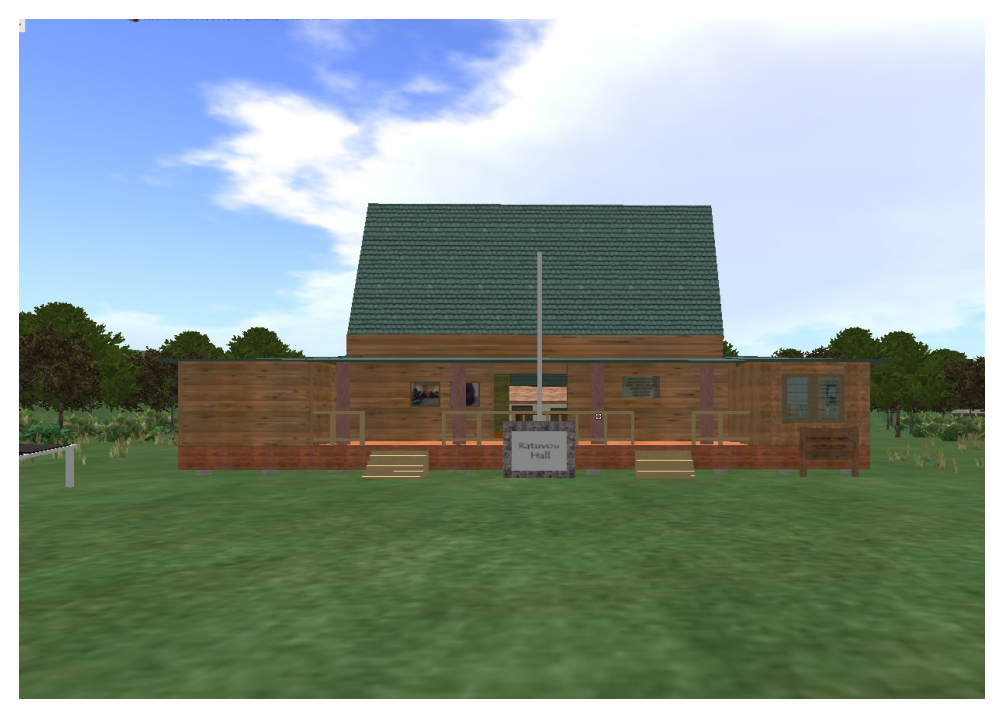

\section{Infusing the virtual island with real-world videos and photographs}

Videos: these were placed on the part of the island where they were recorded.

- They are displayed as a framed image of the person talking in the video. When users left click on the framed image, the video appears in an in-world web browser.

- The video files are stored on the website 'YouTube' which allows the storage and streaming to be free of any charges.

- However, because the people speaking in the videos have requested for these videos not to be publicly available the video files are categorised as 'unlisted' on You Tube. This means that they can only be viewed by those that possess the exact URL (or a hyperlink). Videos categorised as 'unlisted' will not appear in search results, the browser page, nor on the author's channel. Until now this approach has proven effective.

- To also represent the tourists' perspectives of the island in the most authentic manner, two videos posted on You Tube by tourists who visited the study area were also incorporated in the island. These videos portrayed the typical tourist perspective (arriving by small plane and by cruiseship) which the project team did not experience as they arrived using the transfer services often used by local community members.

Photographs: photographs (digital and scanned print photographs) are used in a few cases to:

- emphasise the similarity between the virtual world and the real world,

- or to illustrate a particular scene/activity which is time consuming to replicate in the virtual world (such as a woman washing clothes or fish on a coral reef).

- Photographs are again positioned in the same area where they were taken.

- the photographs are stored digitally on an image hosting server (ImageShack.us), which provides this service at no cost. 
Figure 4 - Example of integration of videos in-world

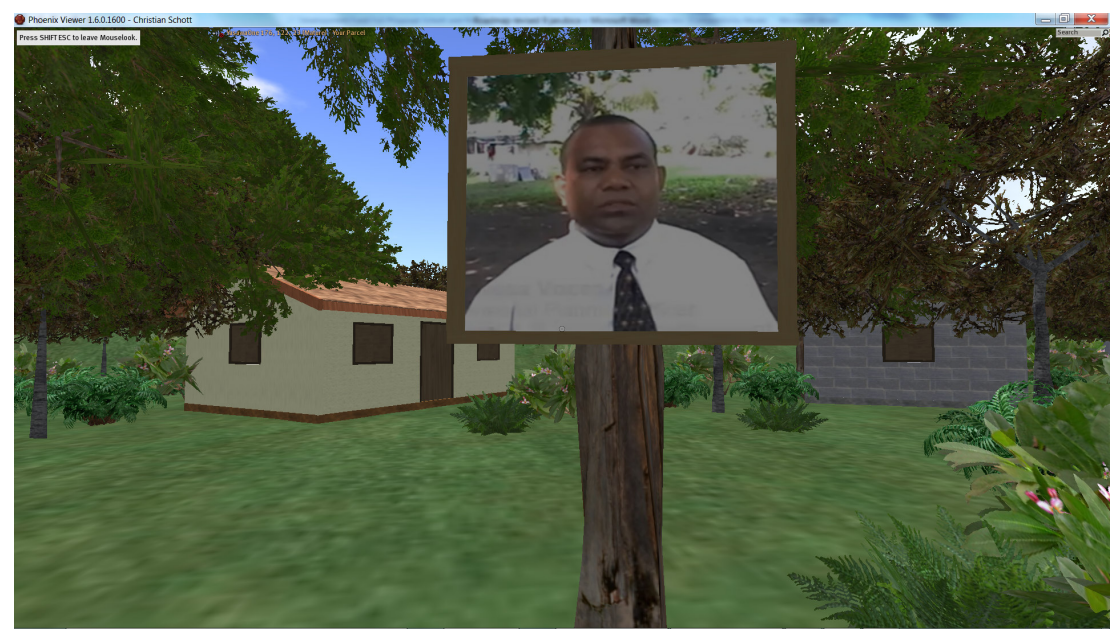

\section{In-world communication between Users}

Open Simulator offers an inbuilt text chat system in which users can send messages to each other through the use of a text field. This is considered a very important facility to allow groups of students to collaborate on the fieldwork tasks while in-world, thus experiencing the same thing. An additional benefit is that they can collaborate in this manner even when group members are several hundred kilometres apart.

- Users can create groups, allowing them to have a discussion with only their group members about their fieldwork task.

- The text chat function also proved very useful during the island's design phase as it allowed the project leader to communicate specific instructions about placement of objects to the technical RA in-world

- Voice chat capabilities have recently been added to the servers that run the NZVWG, which adds quicker communication between users.

\section{Video Illustration of Virtual Island}

To view a 10 minute video illustrating parts of the virtual island please click on this URL:

http://youtu.be/yjSIONrRhmo (delays in the video play back are mostly due to the video (recording and streaming) rather than the virtual reality software)

\section{PROBLEMS AND CHALLENGES ENCOUNTERED}

\section{Cyber Vandalism}

After the project had been piloted as part of TOUR250 the servers hosting the project, and in turn the virtual island itself, was attacked by a hacker. This occurred in early November and amounted to quite detrimental cyber vandalism as numerous random objects were placed on the virtual island and bugs inhibited normal movement of the avatars. As a result, the programme could not be used nor could further refinements to the virtual island be made for a duration of about two months.

○ Solution: Due to the server being hosted at Auckland, Auckland ITS were the only 
ones in a position to solve the problem. Again, Scott Diener and his ITS team at Auckland were very supportive and forthcoming in finding a solution to this attack. The initial solution was to clean the virtual world of any foreign objects and off bugs.

- However, the cleaning process was unsuccessful in two regions which lead to the decision to replace the two regions with earlier copies of the regions, which was successful.

- Because Auckland ITS' attempts to solve the hacking problem were interrupted by several periods when Auckland's core business and responsibilities rightfully took priority it took two months before the programme was fully functional again.

- An approach of countering such attacks in the future is to increase security by for example restricting access to the virtual island; however, it is not clear whether this cyber vandalism attack could have been halted by restricting user access.

\section{Other Problems}

As can be expected for a pilot project of this nature a number of more specific problems were also encountered, which are outlined below. Where possible the solution that proved most effective for this project is highlighted:

- When first using the programme students were removing objects in-world (mostly unintentionally) as well as creating 'random' objects. This occurred when students right clicked (for example to activate a video) instead of left clicking.

- Solution: ensure 'build' privileges are removed from all student users, anchor any objects, and educate students about the need to be careful about any changes and the impacts caused by intentional changes

- Students commonly had to reconfigure the viewer to connect to the NZVWG eventhough the configuration had been successfully completed during previous login on on-campus computers

○ Solution: no solution was found

- Instabilities in the programme's or specific region's accessibility were noted on several occasions. These instances generally only lasted a few hours while the programme was used as part of the course, but did last several days on a couple of occasions in the aftermath of the cyber vandalism attack. In February 2012 occasional instabilities persist.

- Solution: the problem either self-resolved or, more commonly, was resolved by Auckland ITS who are hosting the server. However, because of this project not being core to Auckland University's operations it is understandable that resolving these issues could not always be handled as a priority.

- The installation of Phoenix viewer software, upgrade of the graphics driver and opening of ports (see above) to test whether the student computing machines at VUW could run NZVWG took about three weeks to complete. This was considerably longer than anticipated based on discussions with a variety of people familiar with the required processes.

- Solution: no immediate solution for this is available apart from this road map, which should render replication of this type of project easier and faster to complete

- Discussions with a variety of people indicate that there is currently no investment in digital design for education at VUW and as such current ITS staffing is 'stretched' (both in terms of time and skills) when asked to assist in such projects. 
- The detail of certain objects and environmental features on the virtual island at the time when TOUR250 students were conducting virtual fieldwork on the island would have benefitted from more refinement to foster a clear and comprehensive understanding of the island as well as enhancing the aesthetics of the virtual world.

- Solution: once the TOUR250 virtual fieldtrip was completed, refinement work was conducted for a further month. This work was guided both by input from the project team as well as by student feedback.

\section{KEY RECOMMENDATIONS:}

The project team is strongly of the opinion that virtual fieldtrips, both as a concept and as implemented in this project (using Open Sim), present a very valuable and effective learning tool. This assessment is based on: i) the project team's own assessment of the virtual island and student engagement observed with this virtual learning environment relative to the project aims, ii) the quality of the virtual fieldwork completed by groups of students and iii) informal student feedback about the virtual island as a learning tool. A full analysis of formal research findings on student feedback is beyond the scope of this Roadmap document due to project timeline limitations; research findings will be published in an educational journal at a later stage. It is worth noting at this point, though, that the positive assessment of this pilot project should not be understood to indicate that either the programme or the related student fieldwork tasks are considered 'flawless', but rather the process of reflection and further refinement will continue for many years and, where time and financial support permit, further improvements to the virtual island will be made. Ideas and suggestions about further refinements are not presented here because the focus of the roadmap is documenting the process and the key lessons learnt; however, the project team is happy to discuss these ideas with interested parties.

Based on the experience documented here, the project team's recommendation is to encourage greater use of virtual environments for learning and teaching at VUW. However, further projects seeking to use or develop virtual worlds for teaching \& learning or for research should be supported by increased funding of the necessary hardware (servers) and technical skills (staff with specialist knowledge in digital design) to minimise the amount and severity of problems that may occur. The project team is grateful for the assistance and expert advice provided by the IT teams at Auckland University and VUW, and in particular Dr Scott Diener at Auckland, but suggests that if the server had been hosted at VUW and supported by staff skilled in digital design some problems (as outlined above) would likely have been resolved more quickly, while others may not have occurred in the first place. This recommendation should not be understood to discourage collaboration on projects of this nature. Instead, it is suggested that knowledge exchange and sharing of some resources (incl libraries of digital objects) is very valuable, while critical resources should be available 'in-house' at VUW. 


\section{ACHNOWLEDGEMENTS}

The first acknowledgement and heart-felt gratitude is extended to the people of Yasawa-i-rara and Bukama for their wonderful hospitality and generous invitation for us to learn from their experiences and views. Most significantly, the project team wishes to thank Naele, spokesman of Yasawa-i-rara village and his family for inviting Maciu and Christian into his home and for their extraordinary hospitality. Furthermore, we are grateful for the approval to conduct this research provided by the Spokesman of Yasawa-i-rara, the Chief of Bukama village, the headmen of both villages and all the village elders. We are also grateful to all the community members and other stakeholders for sharing their experiences and views.

The project leader, Dr Christian Schott, would like to thank the other project team members for their valuable expert contributions to the project. A combination of very different 'skill sets' was required to execute this project which raised a variety of challenges; however, the process and outcome serve as an excellent example of the tremendous benefits that can be harnessed from transdisciplinary collaboration (Digital Design, Tourism Management, Development Studies, Pacific Leadership Studies).

Additionally, highlighting the benefits of trans-university collaboration the project team wish to extend a big thank you to Dr Scott Diener (Associate Director, IT Services at Auckland University) and his Digital Design Team who have been instrumental in supporting the development of the virtual fieldtrip concept using NZVWG; both in terms of providing server space and technical support.

At VUW we wish to thank Johnny Flutey (Relationship Services Manager, ITS) for his valuable input during the conceptual stage as well as his support throughout the implementation phase. Also integral to implementing the project at VUW has been Gaetan Pennavayre (ITS) who we thank for his effort and time researching and implementing programme and network requirements. 


\section{REFERENCES}

Dewey, J. (1963). Experience and Education (originally published 1938). New York: Collier.

Jakubowski, L. M. (2003). Beyond book learning: Cultivating the pedagogy of experience through field trips. The Journal of Experiential Education, 26(1):24-33.

Salt, B., Atkins, C. and L. Blackall (2008). Engaging with Second Life: Real Education in a Virtual World. The SLENZ Project for the New Zealand Tertiary Education Commission 2008. Accessible: http://piensl.pbworks.com/f/slliteraturereviewa1.pdf

Scarce, R. (1997). Field trips as short-term experiential education. Teaching Sociology. 25(3): 219217.

Tyson, J. (2008). The Case Planning Pyramid - Australian and New Zealand School of Government Case Programme. Victoria University of Wellington, School of Governement. Provided by the author. 
Appendix 1 Assessment Criteria

\begin{tabular}{|c|c|c|c|c|c|c|}
\hline \multirow[t]{2}{*}{ Assessment Criteria } & \multicolumn{2}{|c|}{$\begin{array}{l}\text { (Authors) } \\
\text { Building }\end{array}$} & \multicolumn{2}{|c|}{$\begin{array}{l}\text { (Instructor) } \\
\text { Maintenance }\end{array}$} & \multicolumn{2}{|c|}{$\begin{array}{l}\text { (Students) } \\
\text { Daily Use }\end{array}$} \\
\hline & Score & Comments & Score & Comments & Score & Comments \\
\hline \multicolumn{7}{|l|}{ User Friendly } \\
\hline \multicolumn{7}{|l|}{ Accessible } \\
\hline \multicolumn{7}{|l|}{ Attractive } \\
\hline \multicolumn{7}{|l|}{ Adaptable } \\
\hline \multicolumn{7}{|l|}{ Accommodates various media formats } \\
\hline \multicolumn{7}{|l|}{ Comprehensivity/Capacity for large amount of detail and material } \\
\hline \multicolumn{7}{|l|}{ Expandability (ability for students to add content in separate area) } \\
\hline \multicolumn{7}{|l|}{ Scale of space (can island $10 \mathrm{~km} * 1 \mathrm{~km}$ be replicated?) } \\
\hline \multicolumn{7}{|l|}{ Versatile } \\
\hline \multicolumn{7}{|l|}{$\begin{array}{l}\text { useable by different disciplines } \\
\text { Cost (start up and annual fees) }\end{array}$} \\
\hline \multicolumn{7}{|l|}{ Time Effectiveness } \\
\hline \multicolumn{7}{|l|}{ Interactivity } \\
\hline \multicolumn{7}{|l|}{ Can learners communicate while in the space? } \\
\hline \multicolumn{7}{|l|}{$\begin{array}{l}\text { Can interactive datasets (modifiable by user) be incorporated? } \\
\text { Level of user control (teleportability, movement control, etc) }\end{array}$} \\
\hline \multicolumn{7}{|l|}{ Other (delete as appropriate) } \\
\hline Longevity \& accessibility of software (will it be around in 5 years?) & & $100 \%$ & $75 \%$ & $50 \%$ & $25 \%$ & $0 \%$ \\
\hline can access be restricted? & & & No & & & \\
\hline \multicolumn{7}{|l|}{ Computer Specifics } \\
\hline Demand on computer Specs (graphics card/processor) & Comme & & & & & \\
\hline demand on Internet connection (if 80 students using at same time) & Comme & & & & & \\
\hline demand on Internet connection (if 40 students using at same time) & Comme & & & & & \\
\hline
\end{tabular}


